\title{
Archetypical opportunities for water governance adaptation to climate change
}

\author{
$\underline{\text { Anastasiia Gotgelf }}^{1}$, Matteo Roggero $^{1}$ and Klaus Eisenack $^{1}$
}

\begin{abstract}
We explore opportunities for climate adaptation in the context of water governance. We focus on opportunities linked to the provision of climate information, raising the question of whether they are limited to incremental adaptation, or can also bring about transformational adaptation. We address this question through an archetype analysis based on 26 peer-reviewed articles. In each article, opportunities are identified, coded using the social-ecological system framework, and then bundled into archetypes that encompass similar opportunities reappearing across multiple cases. Results suggest that the provision of climate information can constitute an opportunity for adaptation that goes beyond purely incremental adjustments to a changing climate. Specifically, two of the six archetypes identified enable transformational adaptation by bringing long-term implications of current impacts into focus and by addressing the issue of capacity of existing institutions to respond to climate change. However, there is a high degree of heterogeneity in the characterization of opportunities, and the six archetypes only cover about one in three of the opportunities identified. This indicates the need for further research to develop more streamlined conceptualizations. In this respect, the archetypes identified herewith suggest some avenues for further conceptual development. We also explore policy implications, raising questions regarding the current development of climate services.
\end{abstract}

Key Words: adaptation; archetypes; climate change; climate information; opportunities; transformation; water governance; water management

\section{INTRODUCTION}

A certain degree of climatic change is unavoidable, even if greenhouse gas emissions were to completely stop as of today (IPCC 2014). This makes adaptation to climate change necessary. Adapting social-ecological systems to a changing climate requires adjustments in both individual and societal behavior (Smit and Wandel 2006). Changes will be needed, both to implement technical solutions and to adjust to those climate impacts that technical solutions cannot fully offset (Adger et al. 2009).

Research into the societal dimension of adaptation focuses on two main lines of inquiry: barriers to adaptation (Moser and Ekstrom 2010) and maladaptation (Juhola et al. 2016). The former addresses the challenges practitioners and decision makers face in responding to increasingly adverse effects of climate variability and change (Biesbroek et al. 2013, Oberlack and Eisenack 2014, Lehmann et al. 2015, Moser et al. 2019). The latter points out that not all adaptation is good (Eriksen et al. 2011); some adaptation processes lead to maladaptive outcomes (Juhola et al. 2016), while others raise fairness and justice concerns (Paavola and Adger 2006, Pelling et al. 2015). In a nutshell, adaptation is difficult to roll out, and may go wrong. Therefore, careful consideration is required before taking measures to overcome barriers to adaptation.

Recent developments call for renewed reflection on these issues. One frequently cited barrier to adaptation is the inadequate provision of climate information to support decision making (Archie et al. 2014, Donatti et al. 2017). However, this barrier is now being overcome as sustained technical and institutional advances in climate modeling (Street 2016, Brasseur and Gallardo 2016, Simpkins 2017) make climate information increasingly accessible to decision makers. In the European context, for instance, a roadmap for climate services (Street 2016) sets out the first steps toward a future where administrations, businesses, and private citizens can easily access climate information. Despite the growing provision of climate information, there often remain challenges in integrating it into decision making and the ambiguity of what sort of adaptation will then follow.

We contribute toward this problem by linking two emerging discourses in the adaptation literature: on opportunities and transformation. The former discourse reflects a growing interest in going beyond a negative discussion of barriers, toward a positive understanding of factors that are currently enabling and shaping adaptation (Biesbroek et al. 2014, Oberlack 2017). The latter acknowledges the increasing importance of distinguishing between incremental and transformational adaptation (Kates et al. 2012, Lonsdale et al. 2015). These considerations enable us to formulate the following research question: Does the provision of climate information provide opportunities for both incremental and transformational adaptation? Or does it lock adaptation governance into either option?

Intuitively, climate information might appear to provide inputs primarily for incremental adaptation, i.e., the consideration of future climatic conditions in present-day decision-making processes. Transformation, by contrast, entails more fundamental alterations in existing governance structures (Pelling and ManuelNavarrete 2011, Godfrey-Wood and Naess 2016), raising issues that go beyond mere availability of information. However, climate information also has a role to play in transformational adaptation. In fact, recent studies suggest that the generation, exchange, and contextualization of climate information is at the very heart of the transformational adaptation agenda (e.g., Tabara et al. 2018). Whether access to climate information provides opportunities for transformational adaptation as well as incremental change is thus a nontrivial question that merits a closer look.

In this paper we explore the links between provision of information and opportunities for incremental and/or 
transformational adaptation in the context of water governance. The water sector is severely affected by climate change (IPCC 2013, Tilleard and Ford 2016) and decision makers in the sector were quick to realize that governance solutions were required, as well as purely technical ones (Gupta and Pahl-Wostl 2013, Huitema et al. 2016). The sector is also characterized by a high degree of heterogeneity and fragmentation (Edelenbos and Teismann 2013, Eisenack 2016). These traits are typical for adaptation in general (Morrison 2017, Den Uyl and Russel 2018), and for transformational adaptation in particular (Lonsdale et al. 2015, Patterson et al. 2017).

Taking account of this heterogeneity, we address the research question using archetype analysis, a methodological approach increasingly gaining traction in sustainability science that enables researchers to develop scientifically valid generalizations about heterogeneous phenomena (Eisenack et al. 2006, Eisenack 2012). In this study, we apply archetype analysis to identify recurring patterns in situations where opportunities for adaptation are observed in the water sector. Subsequently we assess the extent to which these opportunities favor incremental or transformational adaptation. Based on 26 selected case studies on water governance adaptation from around the world, we identify six archetypical situations in which the provision of climate information constitutes an opportunity for adaptation. We find that four archetypes bear the hallmarks of incremental adaptation, while two are associated with transformational adaptation.

\section{KEY CONCEPTS}

Does the provision of climate information constitute an opportunity for both incremental and transformational adaptation in the context of water governance? We draw on a literature review to examine key concepts that underpin our formulation of this research question, i.e., water governance; climate information; adaptation governance; opportunities for adaptation; and incremental and transformational adaptation.

\section{Water governance}

Although water management has traditionally been the remit of central public authorities, contemporary water management is better described by the broader notion of water governance. This term encompasses the interactions among a variety of public and private organizations dealing with water resources at different levels of politico-administrative organization (Brooks 2002, Huntjens et al. 2010, Bressers and Kuks 2013, Pahl-Wostl and Knieper 2014). Water governance is a complex action field, involving different sectors, scales, and domains; it encompasses a complex structure of mutual interdependencies among actors with various interests and views that need to be coordinated (Edelenbos and Teismann 2013, Eisenack 2016).

In this context, the attention of academics and practitioners has shifted away from purely technical approaches to managing water and is now increasingly focused on achieving effective interaction and coordination among all actors involved (Edelenbos and Teisman 2013). This shift is reflected in the range of measures put forward to reduce the sector's vulnerability to climate change: although "hard" technical measures, e.g., raising dikes, have not gone out of fashion, they are increasingly embedded into "soft" approaches, involving spatial planning instruments and promotion of ecosystem-based perspectives ("living with water," "giving space to the river," "good ecological status"). These typically require that higher level water managers cooperate with local authorities (Kirchhoff et al. 2013) and water engineers engage with nature conservation agencies, planners, and affected parties (Bergsma 2016). Although an in-depth exploration of water governance is beyond the scope of this paper, the reader should keep in mind that the water sector has grown in social complexity, making interactions among interdependent actors crucial for the management of water resources.

\section{Climate information and adaptation governance}

As in the case of water governance, climate adaptation in general involves a broad set of actors, who play out in nested governance systems (Bisaro and Hinkel 2016). Adaptation governance corresponds to "collective efforts of multiple societal actors to address problems, or to reap the benefits, associated with impacts of climate change" (Huitema et al. 2016), with the aim of ensuring coordinated action among interdependent actors (Roggero 2015). Collective action faces social dilemmas, and climate adaptation is no exception in this respect (Bisaro and Hinkel 2016). Under the header of barriers to adaptation, scholars have identified many factors that prevent adaptation from taking place (Moser and Ekstrom 2010, Biesbroek 2014, Lehmann et al. 2015, Oberlack 2017). Many of these barriers relate to the provision of climate information.

Climate information refers to externally provided processed data, products, or evidence-based knowledge about the atmosphereocean system (Singh et al. 2018). This climate data originates from diverse sources such as in situ sensor measurements, remote sensing observations, or climate models (Giuliani et al. 2017) and can range from historical data to long-term climate change projections (Soares et al. 2018). Such diversification leads to a wide range of available climate information that can be used in adaptation decision making, different in its origin, form, purpose, scale, or context. The temporal character of such information is particularly important for climate adaptation. Climate information can be divided into three categories: short term (weather forecasts); medium term (seasonal and decadal climate forecasts), and long term (climate variability and climate change projections; Collins 2002, O'Brien and Vogel 2003, Ziervogel et al. 2010). There are important differences between these types of forecasts: weather forecasts predict conditions of the atmosphere, i.e., temperature, precipitation, and air movements, for the next few days, while climate forecasts are based on the statistical average of all weather events over a longer period of time (normally 30 years; Singh et al. 2018).

In the water sector, climate change projections and medium-term climate predictions play the greatest role in preparing strategic, longer term adaptive responses (Ziervogel et al. 2010, Kirchhoff 2013). However, generation of future climate information through modeling or scenario-based approaches (usually using general or regional circulation models and emission scenarios) is often associated with users' concern regarding accuracy of such information (Grygoruk and Rannow 2017) or uncertainty about projected climate impacts (Biesbroek et al. 2014). Scholars have identified a number of further challenges related to the integration of climate information into planning and decision making. These include unwieldy rules that hamper the retrieval, processing, and use of information for decision making (Oberlack and Eisenack 
2018), institutional fragmentation (Cosens et al. 2017, Okpara et al. 2018), lack of collaboration (Bettini et al. 2015) and communication (Azhoni et al. 2017), and inadequate awareness and understanding of climate change (Jones and Boyd 2011, DeCaro et al. 2017).

\section{Opportunities for adaptation}

Within the adaptation literature, two fundamentally different concepts share the label of "opportunity" for adaptation: drivers forcing adaptation (see Shepherd et al. 2006, Pelling and ManuelNavarrete 2011), and factors enabling adaptation (see Lonsdale et al. 2017, Oberlack 2017). The distinction is subtle, but important. For example, an adaptation measure that results from the traumatic experience of a flood is different from one that results from the reorganization of public administration. Both cases represent an opportunity for adaptation. Yet, they represent qualitatively different phenomena: in the former, an unforeseen catastrophic event leads to new perceptions and priorities. In the latter, an organizational measure is taken intentionally to remove a specific barrier to adaptation (see Tompkins et al. 2010).

Both concepts are important and relevant. However, because of space considerations, we focus in this study on opportunities as enabling factors, and specifically on opportunities related to the provision of climate information that help overcome existing barriers to adaptation in the water sector. The rationale for this choice is that opportunities that force adaptation can only be seized upon in a reactive way, however timely this may be. By contrast, removing barriers intentionally requires careful consideration, particularly if doing so can potentially give rise to different types of adaptation. Opportunity in this sense is thus more closely aligned to the topic of our research.

\section{Incremental and transformational adaptation}

The distinction between incremental and transformational adaptation emerged as a topic of interest when climate scholars started to highlight the need for a fundamental change in socioeconomic arrangements in order to adapt to climate change (Tabara et al. 2018), and to question whether the measures currently planned and/or being taken are up to the task (Kates et al. 2012). The defining characteristics of transformational adaptation have been described in different ways: as addressing the root causes of climate vulnerability rather than only its symptoms (Wise et al. 2014); fostering long-term adaptive capacity rather than short-term vulnerability reductions (Wamsler et al. 2013); or changing habits and institutions rather than the physical infrastructure (Vine 2018). All in all, scholars seem to converge around an emphasis on long-term, reflexive adaptation processes.

Precisely drawing the line separating incremental and transformational adaptation has so far proved challenging. In principle, the distinction is similar to one that has been widely discussed in the literature of evolutionary resilience. It is recognized that a resilient social-ecological system can display two different reactions in response to an external shock: it can absorb the shock and "bounce back" to status-quo conditions or, alternatively, "bounce forth" to a new set of conditions that are equally stable and yet fundamentally different (Davoudi et al. 2013). In this sense, incremental adaptation encompasses measures that reproduce or even entrench the status quo in the face of changing conditions. By contrast, transformational adaptation encompasses measures that lead to a new system configuration.

\section{METHODS}

We aim at identifying recurring patterns in situations where opportunities for adaptation are observed in the water sector. Below we provide an overview of the methodology used to generate research insights that are more widely applicable than single-case idiosyncrasies, but also of more practical relevance than overgeneralized panaceas.

\section{Research design and data collection}

We conducted a meta-analysis of 26 systematically selected research articles to identify opportunities to adaptation, using the social-ecological system (SES) framework (Ostrom 2009) to characterize each opportunity identified. Specifically, we used the articles selected by Oberlack and Eisenack (2018) for their study of barriers to adaptation in worldwide water governance (see Appendix 1 for full references). In all these case studies, opportunities for adaptation were also identified, making this selection suitable for the present analysis.

Similar to Oberlack (2017) and Oberlack and Eisenack (2018), our meta-analysis is "model-centered" (Rudel 2008); that is, it focuses on explicit causal statements found in the articles under review, and draws collections of attributes ("models") from each of them. The rationale for this procedure is as follows. Conducting a meta-analysis of multiple case studies carried out by different authors with different goals in mind would ideally involve interviews and/or questionnaires with the authors to fill gaps and establish a degree of homogeneity in the dataset. Doing so is a resource-intensive process and goes beyond the available resources. As an alternative, the model-centered approach represents a viable second-best option. Because models are derived from explicit statements, they require less interpretation than the case study as a whole. Focusing on causal statements clearly represents a reduction of complexity. That should not be overstated, though, first, because causal statements were formulated by experts with case-level knowledge, and second, because they passed the peer-review process, which, with all its limitations, should guarantee a minimum degree of reliability. Third, causal statements should not be overstated because they can represent a substantially large and considerably detailed amount of text.

The last point is crucial. When the phenomenon at stake is wellstudied, model-centered meta-analyses can take a very reductionistic approach to identifying causal statements and drawing models from them (e.g., Oberlack 2017, Oberlack and Eisenack 2018). "Opportunities for climate adaptation," however, is an emerging concept, with little research to rely on. Causal statements shall therefore provide a sufficiently rich description so as to cover the whole situation in which an opportunity for adaptation arises. To this end, we deviate from Oberlack (2017) and Oberlack and Eisenack (2018) and broaden our understanding of causal statements to include the broader account in which they are embedded. Causal statements shall therefore be read as explicit narratives, providing a rich description of how a particular enabling factor (provision of climate information), when coupled with other factors leads to adaptation to climate change. A detailed illustration of how 
Fig. 1. Data analysis flowchart.

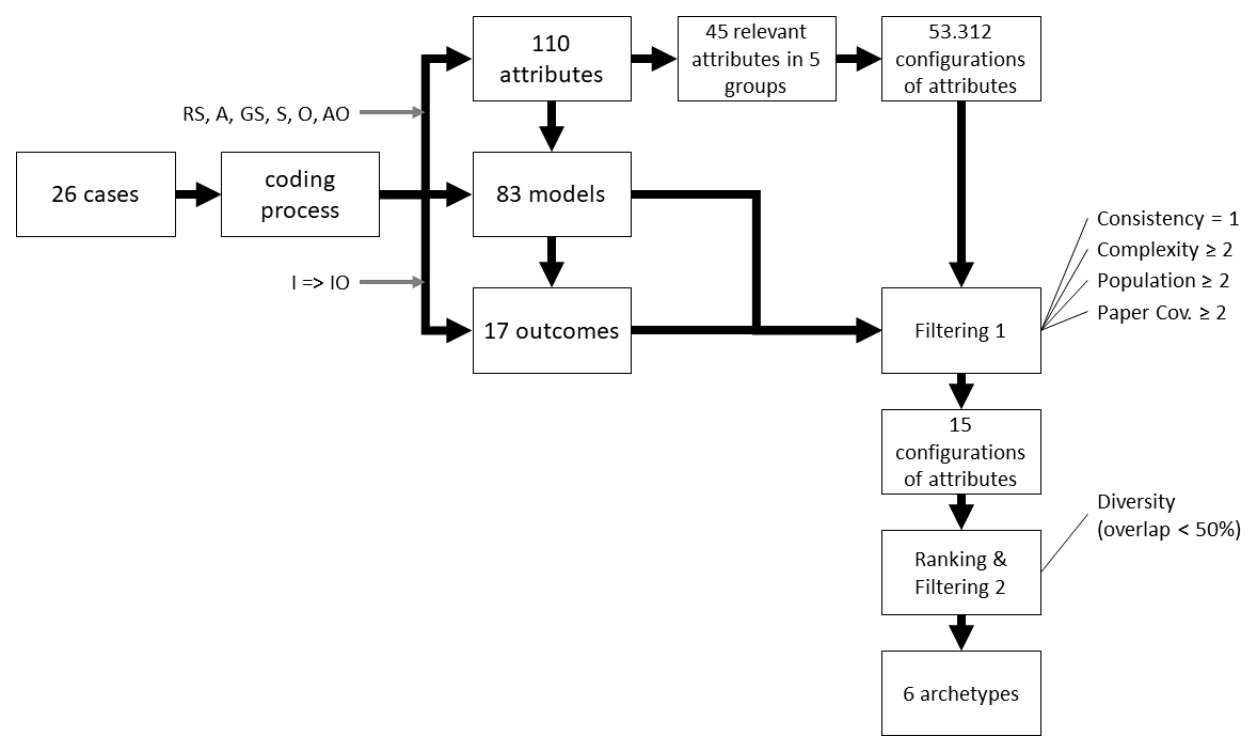

models were extracted from the source material can be found in Appendix 1.

We identified a total of 83 models in the 26 articles under scrutiny. Of these, 38 models describe an opportunity in terms of the provision of climate information. We coded these 38 models employing the common vocabulary of attributes developed by Oberlack and Eisenack (2018), which builds on the SES framework. The SES framework has a multitiered structure that allows opportunities identified to be coded at varying levels of specificity. Moreover, it is very comprehensive and is thus able to accommodate a broad set of very different situations. In a nutshell, the SES framework is both broad and deep and does not impose, ex ante, a specific level of abstraction on the analysis (see Cox 2008). This is useful when exploring potentially very heterogeneous phenomena such as opportunities for adaptation.

Our codebook retains the top-tier of the framework, distinguishing between resource systems (RS), resource units (RU), actor characteristics (A), governance systems (GS), social, economic, and political settings (S), and interactions (in our study labeled IO, so as to reflect opportunities), to which the additional category "adaptation option" (AO) was added. The second and third tiers of the codebook divide each of these categories into a further set of attributes, which were similarly modified by the authors to fit the data. One of the main authors undertook multiple rounds of coding, discussing results with the other authors to ensure inter-rater reliability of coding. Iterations continued until the codebook stabilized. In its final form the codebook comprises 116 attributes; of these, 6 describe the opportunity concerned (IO), and 110 characterizing the factors affecting it, distributed across several tiers of RS, A, GS, S, and AO. Appendix 1 contains detailed information on the final codebook and coding process.

\section{Data analysis}

We employed archetype analysis to explore the 38 models relevant to the provision of climate information, searching for patterns among their attributes. The reader can refer to Oberlack et al. (2019) and Eisenack et al. (2019) for a detailed account of the broader rationale underlying archetype analysis. In the context of the present research, there were two main reasons for our decision to employ archetype analysis. First, opportunities for adaptation can be expected to encapsulate a high level of heterogeneity, particularly in the context of water governance. We therefore needed an analytical approach that favors multiple, contextualized explanations, rather than single, universal ones. Second, we needed an approach that is compatible with multiple levels of abstraction, i.e., the multiple tiers of the SES framework that we employed to organize and structure the data. Archetype analysis fulfills both requirements.

Archetype analysis does not represent an analytical method per se. Rather, it is an approach compatible with multiple analytical methods (Sietz et al. 2019). It provides guidelines on how to structure an analysis in order to systematically search for possible attribute configurations (here the 110 attributes of the modified SES framework) in a given set of observations (here the 38 models of adaptation linked to the provision of climate information). Figure 1 shows how the guidelines for archetype analysis were translated into a procedure, leading from the characterization of the models to the identification of the archetypes. A full description procedure can be found in Appendix 1; here we summarize its most important features:

- From the original list of 110 attributes, we removed those that were observed in fewer than three models, leaving a total of 45 . Subsequently, all theoretically possible configurations of these 45 attributes encompassing one attribute from each SES element (including no attribute) were computed.

- The resulting 53,312 theoretically possible configurations were then filtered based on four criteria: (1) whether they identify models that consistently feature opportunities for adaptation that involve the provision of climate information ("consistency"); (2) whether they were reoccurring, i.e., 
observed in at least two models ("population"), (3) from at least two different papers ("coverage"); and (4) whether they encompassed at least two different SES elements ("complexity"),

- This process resulted in a list of 15 configurations that were then ranked based on their complexity (number of attributes) and population (the number of models). The resulting ranking was used to structure pairwise comparisons between configurations to remove those that overlapped beyond a fixed threshold $(50 \%)$. This resulted in the final list of six archetypes, described below.

The analysis was done using $\mathrm{R}$ ( $\mathrm{R}$ Core Team 2018). The derived archetypes satisfy the quality criteria for archetype analysis (Eisenack et al. 2019), namely: (1) they have a clear domain of validity (water governance); (2) they are not mutually exclusive (individual models can be instances of multiple archetypes, even though no two archetypes can cover exactly the same set of models); and (3) they are reoccurring (the corresponding models must appear in at least two different papers).

\section{RESULTS}

This section presents the six archetypes that were identified using the procedure outlined above, and completes the archetype analysis by describing the theories underpinning them.

\section{Adaptation as collective action}

This archetype reflects the combination of three attributes: "joint institutional arrangements," "trust building among actors," and "horizontal coordination"; it was observed in two different models from two different papers. Joint institutional arrangements, trust building among actors, and horizontal coordination are key descriptors of collective action, which has been a central theme in the literature on adaptation (Marshall 2013, Bisaro and Hinkel 2016). Scholars particularly stress the importance of interdependencies among actors and the crucial role of social dynamics in building adaptive capacity (Adger 2003). We observed this archetype in the context of transboundary water governance, where water management is typically fragmented. Coordination between the parties and the presence of common institutional frameworks are essential to enable adaptation. Establishment of joint institutions helps to reconcile multiple interests, balance priorities, and shape a favorable environment for the integration of climate information into decision making and design of feasible management interventions (Kistin and Ashton 2008).

\section{Adaptation through local knowledge}

The attributes making up this archetype are "local watershed units" and "awareness of climate change impacts," appearing in three models across three papers. This archetype highlights the link between the "local" dimension of the watershed concerned and impacts of climate change. It thus encompasses those branches of the adaptation literature addressing the (single) "level" of socioeconomic organization best suited to deliver adaptation and stressing that local actors know best how climate change translates into impacts (Brooks 2002, Agrawal 2008, Nordgren et al. 2016). At the local level, climate impacts might be grasped more easily, which gives climate concerns a higher chance to be integrated into management practices. Experience of local-level vulnerability to climate change motivates actors to integrate climate information into water management practices and deliver effective responses (O'Connor et al. 1999). Adaptation here takes place within existing practices.

\section{Adaptation "fit"}

This archetype describes the combination of "local watershed units" and "institutional incentives and priorities." It represents three models from two different papers. Like the previous one, this archetype reflects the scholarly debates on the most appropriate level of adaptation. Here, however, the focus is on the alignment of institutional incentives with the requirements for local-level adaptation in response to climate impacts experienced at this level. This relates to a broader debate in the literature on environmental governance regarding the correspondence between institutional boundaries and the costs and benefits linked to managing particular resources (Young 2002, Young 2010), a topic that adaptation scholars have also addressed (Farber 2009, Shobe and Burtraw 2012). From this perspective, the provision of climate information represents an opportunity for adaptation if it is provided in a way that fits with the interests and mandates of the (local) actors concerned (Whitely Binder 2006, Hamlet 2011, Hurlbert and Diaz 2013).

\section{Knowledge in context}

The attributes characterizing this archetype are "local watershed units" and "available data on climate projections at the local scale," identifying two models from two different papers. Climate research literature on scenario building highlights the need for highly contextualized knowledge for decision making (Cohen 1990, Hostetler 1994, Grimmond et al. 2010). It is often difficult for decision makers to know how to respond to low-resolution climate projections. In contrast, opportunities for adaptation emerge when climate information is provided at a local scale (O'Connor et al. 1999, Whitely Binder 2006). Speaking the language of local climate impacts makes climate information more accessible to decision makers, and more relevant to existing mindsets, institutions, and biophysical particularities (Füssel 2007).

\section{System evolution}

Combining "current climate stimuli" and "long-term focus," this archetype reflects two models from two papers. Literature at the intersection between resilience and climate adaptation highlights the need for adaptation to climate change to be informed by a vision of the long-term development of the social-ecological system concerned (Tschakert and Dietrich 2010, Davoudi et al. 2013). In this sense, opportunities for supporting long-term and effective adaptation arise from the coproduction of useful knowledge as a result of collaboration between scientists and stakeholders (Kirchhoff et al. 2013, Pulwarty and Maia 2015). Such direct collaboration between stakeholders and climate scientists aims at improving stakeholders' understanding of climatic stimuli and its impacts on the governed water system. It reconciles information supply and concrete demand needs by integrating expertise from both sides, which leads to increased capacity while dealing with adaptation related problems. This kind of partnership implies long-term iterative interactions that allows for advancing formal and informal networks, and therefore is likely to result in successful and sustainable societal outcomes. Specifically, such collaborations go beyond the mere planning of individual measures, directly impacting regional policies and 
promoting development of new communities of practices (as in Wilder et al. 2010).

\section{Learning}

This archetype combines "awareness of climate impacts" and "institutional incentives and priorities" as observed in two models from two papers. Much of the literature on adaptation focuses on learning, stressing how adaptation often needs to be compatible with shared beliefs about the workings of the social-ecological system (Pahl-Wostl 2009, Baird et al. 2014). Learning plays a crucial role in shaping actors' behavior, particularly when regulatory arrangements are unwieldy and complex, and/or insufficient on their own to foster the direct integration of climate change concerns in formal decision-making processes (Storbjörk 2010). The key insight is that learning ensures a higher level of awareness of climate impacts among managers and decision makers. It enables actors to circumvent institutional barriers to adaptation by exploiting flexibility in existing arrangements and seeking synergies with other institutional arrangements. For example, recognition of potential adverse effects of climate variability on a resource system and of the need for a tailored climate information may result in seizing opportunities by integrating climate change issues into decision making under the umbrella of related existing institutional mechanisms that prioritize efficient use and conservation of water resources (Boer 2010, Farley et al. 2011). This leads to a higher adaptive capacity in terms of increasing institutional flexibility and ensures longterm, reflexive adaptation.

\section{DISCUSSION}

Our archetype analysis identifies six recurring situations in which opportunities for adaptation in water governance arise. The analysis focuses specifically on opportunities linked to the provision of climate information and whether these opportunities are for incremental or transformational adaptation. Results suggest that the provision of climate information is not limited to adaptations consisting of incremental, marginal changes in existing practices, but are also associated with transformational adaptation. Specifically, two of the six archetypes identified, "System evolution" and "Learning," enable transformational adaptation, in the former as a result of the focus on long-term implications of current impacts, and in the latter arising from reflection among actors on how to address climate impacts in the context of available institutional arrangements. These two archetypes fit well into narratives characterizing transformational adaptation as adaptation that (1) focuses on reducing future vulnerabilities rather than simply preserving present conditions; and (2) questions the capacity of existing institutions to respond to climate change (Mustelin and Handmer 2013, Lonsdale et al. 2015).

In relation to the overarching research question addressed by this study, these results are encouraging: they suggest that the provision of climate information can constitute an opportunity for adaptation that goes beyond purely incremental adjustments to a changing climate. This result is particularly encouraging in the light of the current situation, where barriers to adaptation translate into a lack of tangible adaptation measures on the ground (Berrang-Ford et al. 2011). Although uncertainty, ambiguity, and lack of information are known barriers to adaptation, the opportunities that emerge to overcome such barriers are apparently not restricted to incremental adaptation. Removing barriers through the provision of climate information will not, it seems, lock adaptation governance into an incremental approach. At least under certain circumstances, it can also give rise to transformational change.

Given the exploratory nature of this study, it seems too early to draw conclusions from the actual composition of the archetypes identified here. Instead, it is probably safer to regard them as starting points for further research. From this perspective, with reference to the two "transformational" archetypes highlighted above, advancements in the conceptualization of opportunities for adaptation shall be linked to the way social-ecological systems evolve over time and to possibilities for double and triple-loop learning as a key step toward change. With reference to the other "incremental" archetypes, advancements seem to lie on collective action, as well as on matters of scale, given that three of the remaining four archetypes stress the local dimension of the resource unit. Future research will tell if developing concepts of opportunities for adaptation along these lines will align with empirical observation.

By focusing primarily on the analysis of opportunities for climate adaptation, the present study identifies archetypical situations in which integration of climate information constitutes an opportunity for adaptation and on the nature of adaptation that follows. Given the increasing amount of available climate information for adaptation decision making, it is worthwhile for future research to consider how different types of climate information are used in different ways and can thus influence opportunities for adaptation. There are already first attempts in this direction (Haasnoot et al. 2012, Singh et al. 2018, Hinkel et al. 2019). The archetype approach may also play a role here by informing the development of climate services, for instance by providing tailored climate products and information.

With a rapid development in provision of environmental information as well as in all kinds of information and communication technologies, processing and constantly governing growing amounts of data has become increasingly challenging. The case of information provision for climate adaptation is certainly no exception. Several questions emerge: what new data should be gathered? Who is responsible for collecting and processing the data, coordination of databases, and dissemination of information? How can this data and information be shared and combined to ensure more sustainable decision making and how the impact can be monitored? We are thus about to observe a great shift in the role information is playing within the governance context. A further link to the emerging field of research in informational governance and environmental sustainability is worth exploring as well (Soma et al. 2016, Giuliani et al. 2017).

Having outlined the implications of the present analysis for adaptation research, we can now tentatively explore the policy implications. The fact that the provision of climate information can enable transformational adaptation calls for policy support in boosting collaborative processes and social learning, e.g., building knowledge hubs (Ziervogel et al. 2016). Leaving aside the distinction between incremental and transformational adaptation, the overarching message emerging from the archetypes seems to be that opportunities for adaptation arise 
when the provision of climate information is embedded in a broader process. In this respect, current efforts by policy makers to establish new climate services and further develop existing ones are a welcome development, which may well contribute to boosting adaptation. These efforts are more likely to facilitate adaptation if policy makers adopt a process orientation (Brasseur and Gallardo 2016). However, judging from initiatives such as the European roadmap for climate services, at present there is a focus on developing markets for climate services (Street 2016), thus making them product oriented. It remains to be seen whether these efforts will be successful in promoting adaptation, or whether they will give rise to new barriers.

A limitation of this research is that the analysis focuses on research papers dealing with water governance, a field where both adaptation and transformation are well-established concepts. Although this is convenient for our analysis, it also limits the external validity of our results: opportunities for adaptation in other sectors such as developmental aid or agriculture may look very different. This is particularly the case for the two transformational archetypes whose specific features are closely linked to water management discourses such as adaptive management and social learning.

Furthermore, the fact of relying on a rather specific field such as water governance may prove a double-edged sword. On the one hand, it may facilitate the emergence of archetypes, given the similarity of perspectives within a narrowly defined epistemic community. On the other hand, it may also be a source of blind spots in the analysis: articles will not report about those things water governance scholars are not interested in. This is a general problem for meta-analyses. It may be less of an issue here, though, given the tendency of governance scholars toward rich case description.

A further limitation is that the analysis focuses on literature addressing barriers to adaptation, not opportunities. This was unavoidable, given the scant attention adaptation scholars have so far given to opportunities. The implications of relying on articles about barriers to adaptation are two-fold. First, scientific publications have limited space: given that opportunities were not the main focus of the papers, one cannot help wondering whether some opportunities, and if so how many, did not make it into the final manuscripts because of space limitations. Second, it becomes difficult to disentangle opportunities and barriers: opportunities identified by our research may, to some extent, simply be mirror images of the barriers the same articles report upon.

Some considerations are due concerning the low number of models covered by the six archetypes; specifically, opportunities linked to the provision of climate information were identified in 13 models out of 38 . Given that the archetypes were constructed inductively and not deductively (that is, they were not formulated on the basis of prior knowledge), this is quite remarkable. Moreover, models were grouped on the basis of shared general characteristics, i.e., higher tier attributes of the SES framework, whenever they diverged with regard to details (lower tier attributes). This procedure resulted in archetypes characterized by rather general attributes, and yet even these covered only two or three models in each case. This suggests that opportunities for climate adaptation represent a very heterogeneous research field. A certain degree of convergence, and development of more streamlined conceptualizations, can be expected as the field reaches maturity. Time will tell whether future research using more sophisticated conceptual approaches enables the identification of suites of archetypes that provide a better coverage of the observed models.

Despite these limitations, this study confirms the ability of archetype analysis to identify and meaningfully interpret patterns of attributes in a very heterogeneous field. It is thus a promising approach for application in a field such as climate adaptation in the water governance sector where context dependence makes it extremely difficult to draw lessons that are valid beyond the individual case study. Archetype analysis has the potential to deliver research insights at an intermediate level of abstraction: more widely applicable than single-case idiosyncrasies, but also of more practical relevance than overgeneralized panaceas.

\section{CONCLUSION}

In this study we explored opportunities for climate adaptation in the context of water governance. We focused on opportunities arising from the provision of climate information. Further, we asked whether these are limited to opportunities for incremental adaptation, or whether provision of climate information can also give rise to transformational adaptation. To address this question, we carried out an archetype analysis of opportunities for adaptation described in 26 peer-reviewed research articles. In each article, opportunities were searched for, coded using the SES framework, and finally bundled into archetypes that encompass similar opportunities reappearing across multiple cases. Six such archetypes were identified, each one representing an opportunity for adaptation characterized by a distinct set of attributes. Two of these archetypes are associated with specific narratives in the discourse on transformational adaptation, suggesting that opportunities for adaptation linked to the provision of climate information are not necessarily limited to incremental adaptation. However, the results display a high degree of heterogeneity in the characterization of opportunities, indicating the need for further research to develop more streamlined conceptualizations of the phenomenon. The results of this study suggest some avenues toward further conceptual development that could be explored by future studies of opportunities for climate adaptation.

\section{Responses to this article can be read online at: http://www.ecologyandsociety.org/issues/responses. php/11768}

\section{Acknowledgments:}

We want to thank Christoph Oberlack and Susanne Moser as well as two anonymous reviewers for their useful comments on previous versions of this manuscript. The research was funded by the state of Berlin's Elsa-Neumann-Scholarship. We acknowledge support by the German Research Foundation (DFG) and the Open Access Publication Fund of Humboldt-Universität zu Berlin.

Data Availability:

Data sharing is not applicable to this article because no new data were created or analyzed in this study. 


\section{LITERATURE CITED}

Adger, W. N. 2003. Social capital, collective action, and adaptation to climate change. Economic Geography 79:387-404. https://doi.org/10.1111/j.1944-8287.2003.tb00220.x

Adger, W. N., S. Dessai, M. Goulden, M. Hulme, I. Lorenzoni, D. R. Nelson, L. O. Naess, J. Wolf, and A. Wreford. 2009. Are there social limits to adaptation to climate change? Climatic Change 93:335-354. https://doi.org/10.1007/s10584-008-9520-z

Agrawal, A. 2008. The role of local institutions in adaptation to climate change. Paper prepared for the Social Dimensions of Climate Change, Social Development Department, The World Bank, Washington, D.C., USA. https://doi.org/10.1596/28274

Archie, K. M., L. Dilling, J. B. Milford, and F. C. Pampel. 2014. Unpacking the 'information barrier': comparing perspectives on information as a barrier to climate change adaptation in the interior mountain West. Journal of Environmental Management 133:397-410. https://doi.org/10.1016/j.jenvman.2013.12.015

Azhoni. A., I. Holman, and S. Jude. 2017. Adapting water management to climate change: institutional involvement, interinstitutional networks and barriers in India. Global Environmental Change 44:144-157. https://doi.org/10.1016/j.gloenvcha.2017.04.005

Baird, J., R. Plummer, C. Haug, and D. Huitema. 2014. Learning effects of interactive decision-making processes for climate change adaptation. Global Environmental Change 27:51-63. https://doi.org/10.1016/j.gloenvcha.2014.04.019

Bergsma, E. 2016. Changed knowledge requirements for spatial flood governance. Ecology and Society 21(4):40. https://doi. org/10.5751/ES-08952-210440

Berrang-Ford, L., J. D. Ford, and J. Paterson. 2011. Are we adapting to climate change? Global Environmental Change 21:25-33. https://doi.org/10.1016/j.gloenvcha.2010.09.012

Bettini, Y., R. R. Brown, and F. J. De Haan. 2015. Exploring institutional adaptive capacity in practice: examining water governance adaptation in Australia. Ecology and Society 20(1):47. https://doi.org/10.5751/ES-07291-200147

Biesbroek, G. R. 2014. Challenging barriers in the governance of climate change adaptation. Dissertation. Wageningen University, Wageningen, The Netherlands.

Biesbroek, G. R., J. E. M. Klostermann, C. J. A. M. Termeer, and P. Kabat. 2013. On the nature of barriers to climate change adaptation. Regional Environmental Change 13:1119-1129. https://doi.org/10.1007/s10113-013-0421-y

Biesbroek, G. R., C. J. A. M. Termeer, J. E. M. Klosermann, and P. Kabat. 2014. Analytical lenses on barriers in the governance of climate change adaptation. Mitigation and Adaptation Strategies for Global Change 19:1011-1032. https://doi.org/10.1007/ $\underline{\text { s11027-013-9457-z }}$

Bisaro, A., and J. Hinkel. 2016. Governance of social dilemmas in climate change adaptation. Nature Climate Change 6:354-359. https://doi.org/10.1038/nclimate2936

Boer, H. 2010. Policy options for, and constraints on, effective adaptation for rivers and wetlands in northeast Queensland. Australasian Journal of Environmental Management 17 (3):154-164. https://doi.org/10.1080/14486563.2010.9725262
Brasseur, G. P., and L. Gallardo. 2016. Climate services: lessons learned and future prospects. Earth's Future 4:79-89. https://doi. org/10.1002/2015EF000338

Bressers, H., and S. Kuks. 2013. Water governance regimes: dimensions and dynamics. International Journal of Water Governance 1:133-156. https://doi.org/10.7564/12-IJWG1

Brooks, D. B. 2002. Water, local-level management. International Development Research Center, Ottawa, Ontario, Canada.

Cohen, S. J. 1990. Bringing the global warming issue closer to home: the challenge of regional impact studies. Bulletin of the American Meteorological Society 71(4):520-526. https://doi. org/10.1175/1520-0477(1990)071<0520:BTGWIC >2.0.CO;2

Collins, M. 2002. Climate predictability on interannual to decadal time scales: the initial value problem. Climate Dynamics 19 (8):671-692. https://doi.org/10.1007/s00382-002-0254-8

Cosens, B. A., R. K. Craig, S. Hirsch, C. A. (T.) Arnold, M. H. Benson, D. A. DeCaro, A. S. Garmestani, H. Gosnell, J. Ruhl, and E. Schlager. 2017. The role of law in adaptive governance. Ecology and Society 22(1):30. https://doi.org/10.5751/ES-08731-220130

Cox, M. 2008. Balancing accuracy and meaning in common-pool resource theory. Ecology and Society 13(2):44. https://doi. org/10.5751/ES-02683-130244

Davoudi, S., E. Brooks, and A. Mehmood. 2013. Evolutionary resilience and strategies for climate adaptation. Planning Practice \& Research 28:307-322. https://doi.org/10.1080/02697459.2013.787695

DeCaro, D. A., C. A. (T.) Arnold, E. F. Boamah, and A. S. Garmestani. 2017. Understanding and applying principles of social cognition and decision making in adaptive environmental governance. Ecology and Society 22(1):33. https://doi. org/10.5751/ES-09154-220133

Den Uyl, R. M., and D. J. Russel. 2018. Climate adaptation in fragmented governance settings: the consequences of reform in public administration. Environmental Politics 27:341-361. https:// doi.org/10.1080/09644016.2017.1386341

Donatti, C. I., C. A. Harvey, M. R. Martinez-Rodriguez, R. Vignola, and C. M. Rodriguez. 2017. What information do policy makers need to develop climate adaptation plans for smallholder farmers? The case of Central America and Mexico. Climatic Change 141:107-121. https://doi.org/10.1007/s10584-016-1787-X

Edelenbos, J., and G. Teisman. 2013. Water governance capacity: the art of dealing with a multiplicity of levels, sectors and domains. International Journal of Water Governance 1:89-108. https://doi.org/10.7564/12-IJWG5

Eisenack, K. 2012. Archetypes of adaptation to climate change. Pages 107-122 in M. Glaser, G. Krause, B. M. W. Ratter, and M. Welp, editors. Human/nature interactions in the Anthropocene: potentials of social-ecological systems analysis. Routledge, New York, New York, USA. https://doi.org/10.4324/9780203123195

Eisenack, K. 2016. Institutional adaptation to cooling water scarcity for thermoelectric power generation under global warming. Ecological Economics 124:153-163. https://doi. org/10.1016/j.ecolecon.2016.01.016

Eisenack, K., M. Lüdeke, and J. Kropp. 2006. Construction of archetypes as a formal method to analyze social-ecological 
systems. In IDGEC Synthesis Conference of the Institutional Dimensions of Global Environmental Change. Bali, Indonesia, Dec 6-9. International Human Dimensions Programme of Global Environmental Change, Bonn, Germany. [online] URL: https:// uol.de/fileadmin/user upload/wire/fachgebiete/envdev/download/ arch-eisenack3.pdf

Eisenack, K., S. Villamayor-Tomas, G. Epstein, C. Kimmich, N. Magliocca, D. Manuel-Navarrete, C. Oberlack, M. Roggero, and D. Sietz. 2019. Design and quality criteria for archetype analysis. Ecology and Society 24(3):6. https://doi.org/10.5751/ES-10855-240306

Eriksen, S., P. Aldunce, C. S. Bahinipati, R. D'Almeida Martins, J. I. Molefe, C. Nhemachena, K. O'Brien, F. Olorunfemi, J. Park, L. Sygna, and K. Ulsrud. 2011. When not every response to climate change is a good one: identifying principles for sustainable adaptation. Climate and Development 3:7-20. https://doi. org/10.3763/cdev.2010.0060

Farber, D. A. 2009. Climate adaptation and federalism: mapping the issues. San Diego Journal of Climate \& Energy Law 259.

Farley, K. A., C. Tague, and G. E. Grant. 2011. Vulnerability of water supply from the Oregon Cascades to changing climate: linking science to users and policy. Global Environmental Change 21(1):110-122. https://doi.org/10.1016/j.gloenvcha.2010.09.011

Füssel, H.-M. 2007. Vulnerability: a generally applicable conceptual framework for climate change research. Global Environmental Change 17:155-167. https://doi.org/10.1016/j. gloenvcha.2006.05.002

Giuliani, G., S. Nativi, A. Obregon, M. Beniston, and A. Lehmann. 2017. Spatially enabling the Global Framework for Climate Services: reviewing geospatial solutions to efficiently share and integrate climate data \& information. Climate Services 8:44-58. https://doi.org/10.1016/j.cliser.2017.08.003

Godfrey-Wood, R., and L. O. Naess. 2016. Adapting to climate change: transforming development? Institute of Development Studies Bulletin: Transforming Development Knowledge 47:49-62. https://doi.org/10.19088/1968-2016.131

Grimmond, C. S. B., M. Roth, T. R., Oke, Y. C. Au, M. Best, R. Betts, G. Carmichael, H. Cleugh, W. Dabberdt, R. Emmanuel, E. Freitas, K. Fortuniak, S. Hanna, P. Klein, L. S. Kalkstein, C. H. Liu, A. Nickson, D. Pearlmutter, D. Sailor, and J. Voogt. 2010. Climate and more sustainable cities: climate information for improved planning and management of cities (producers/ capabilities perspective). Procedia Environmental Sciences 1:247-274. https://doi.org/10.1016/j.proenv.2010.09.016

Grygoruk, M., and S. Rannow. 2017. Mind the gap! Lessons from science-based stakeholder dialogue in climate-adapted management of wetlands. Journal of Environmental Management 186:108-119. https://doi.org/10.1016/j.jenvman.2016.10.066

Gupta, J., and C. Pahl-Wostl. 2013. Editorial on global water governance. Ecology and Society 18(4):54. https://doi. org/10.5751/ES-06115-180454

Haasnoot, M., H. Middelkoop, A. Offermans, E. van Beek, and W. A. van Deursen. 2012. Exploring pathways for sustainable water management in river deltas in a changing environment. Climatic Change 115:795-819. https://doi.org/10.1007/s10584-012-0444-2
Hamlet, A. F. 2011. Assessing water resources adaptive capacity to climate change impacts in the Pacific Northwest Region of North America. Hydrology and Earth System Sciences 15:1427-1443. https://doi.org/10.5194/hess-15-1427-2011

Hinkel, J., J. A. Church, J. M. Gregory, E. Lambert, G. Le Cozannet, J. Lowe, K. L. McInnes, R. J. Nicholls, T. D. van der Pol, and R. van der Wal. 2019. Meeting user needs for sea level rise information: a decision analysis perspective. Earth's Future 7:320-337. https://doi.org/10.1029/2018EF001071

Hostetler, S. W. 1994. Hydrologic and atmospheric models: the (continuing) problem of discordant scales. Climatic Change 27:345-350. https://doi.org/10.1007/BF01096266

Huitema, D., W. N. Adger, F. Berkhout, E. Massey, D. Mazmanian, S. Munaretto, R. Plummer, and C. C. J. A. M. Termeer. 2016. The governance of adaptation: choices, reasons, and effects. Introduction to the Special Feature. Ecology and Society 21(3):37. https://doi.org/10.5751/es-08797-210337

Huntjens, P., C. Pahl-Wostl, and J. Grin. 2010. Climate change adaptation in European river basins. Regional Environmental Change 10:263-284. https://doi.org/10.1007/s10113-009-0108-6

Hurlbert, M. A., and H. Diaz. 2013. Water governance in Chile and Canada: a comparison of adaptive characteristics. Ecology and Society 18(4):61. https://doi.org/10.5751/ES-06148-180461

Jones, L., and E. Boyd. 2011. Exploring social barriers to adaptation: insights from Western Nepal. Global Environmental Change 21:1262-1274. https://doi.org/10.1016/j.gloenvcha.2011.06.002

Juhola, S., E. Glaas, B.-O. Linnér, and T.-S. Neset. 2016. Redefining maladaptation. Environmental Science \& Policy 55:135-140. https://doi.org/10.1016/i.envsci.2015.09.014

Intergovernmental Panel on Climate Change (IPCC). 2013. Summary for Policymakers. In T. F. Stocker, D. Qin, G.-K. Plattner, M. Tignor, S. K. Allen, J. Boschung, A. Nauels, Y. Xia, V. Bex, and P. M. Midgley, editors. Climate change 2013: the physical science basis. Contribution of Working Group I to the Fifth Assessment Report of the Intergovernmental Panel on Climate Change. Cambridge University Press, Cambridge, UK. https:// doi.org/10.1017/cbo9781107415324.004

Intergovernmental Panel on Climate Change (IPCC). 2014. Summary for policymakers. Pages 1-32 in C. B. Field, V. R. Barros, D. J. Dokken, K. J. Mach, M. D. Mastrandrea, T. E. Bilir, M. Chatterjee, K. L. Ebi, Y. O. Estrada, R. C. Genova, B. Girma, E. S. Kissel, A. N. Levy, S. MacCracken, P. R. Mastrandrea, and L. L. White, editors. Climate change 2014: impacts, adaptation, and vulnerability. Part A: global and sectoral aspects. Contribution of Working Group II to the Fifth Assessment Report of the Intergovernmental Panel on Climate Change. Cambridge University Press, Cambridge, UK. https://doi.org/10.1017/ cbo9781107415379.003

Kates, R. W., W. R. Travis, and T. J. Wilbanks. 2012. Transformational adaptation when incremental adaptations to climate change are insufficient. Proceedings of the National Academy of Sciences 109:7156-7161. https://doi.org/10.1073/ pnas. 1115521109 
Kirchhoff, C. J. 2013. Understanding and enhancing climate information use in water management. Climatic Change 119:495-509. https://doi.org/10.1007/s10584-013-0703-x

Kirchhoff, C. J., M. C. Lemos, and N. L. Engle. 2013. What influences climate information use in water management? The role of boundary organizations and governance regimes in Brazil and the U.S. Environmental Science \& Policy 26:6-18. https://doi. org/10.1016/j.envsci.2012.07.001

Kistin, E. J., and P. J. Ashton. 2008. Adapting to change in transboundary rivers: an analysis of treaty flexibility on the Orange-Senqu River Basin. International Journal of Water Resources Development 24:385-400. https://doi.org/10.1080/079$\underline{00620802127325}$

Lehmann, P., M. Brenck, O. Gebhardt, S. Schaller, and E. Süßbauer. 2015. Barriers and opportunities for urban adaptation planning: analytical framework and evidence from cities in Latin America and Germany. Mitigation and Adaptation Strategies for Global Change 20:75-97. https://doi.org/10.1007/s11027-013-9480-0

Lonsdale, K., P. Pringle, and B. Turner. 2015. Transformative adaptation: what it is, why it matters \& what is needed. UK Climate Impacts Programme, University of Oxford, Oxford, UK. [online] URL: https://ukcip.ouce.ox.ac.uk/wp-content/PDFs/UKCIPtransformational-adaptation-final.pdf

Lonsdale, W. R., H. E. Kretser. C.-L. B. Chetkiewicz, and M. S. Cross. 2017. Similarities and differences in barriers and opportunities affecting climate change adaptation action in four North American landscapes. Environmental Management 60:1076-1089. https://doi.org/10.1007/s00267-017-0933-1

Marshall, G. R. 2013. Transaction costs, collective action and adaptation in managing complex social-ecological systems. Ecological Economics 88:185-194. https://doi.org/10.1016/j. ecolecon.2012.12.030

Morrison, T. H. 2017. Evolving polycentric governance of the Great Barrier Reef. Proceedings of the National Academy of Sciences 114:3013-3021. https://doi.org/10.1073/pnas.1620830114

Moser, S. C., and J. A. Ekstrom. 2010. A framework to diagnose barriers to climate change adaptation. Proceedings of the National Academy of Sciences 107:22026-22031. https://doi.org/10.1073/ pnas. 1007887107

Moser, S. C., J. A. Ekstrom, J. Kim, and S. Heitsch. 2019. Adaptation finance archetypes: local governments' persistent challenges of funding adaptation to climate change and ways to overcome them. Ecology and Society 24(2):28. https://doi. org/10.5751/es-10980-240228

Mustelin, J., and J. Handmer. 2013. Triggering transformation: managing resilience or invoking real change? Pages 24-32 in Proceedings of transformation in a changing climate conference, 19-21 June, University of Oslo, Norway.

Nordgren, J., M. Stults, and S. Meerow. 2016. Supporting local climate change adaptation: where we are and where we need to go. Environmental Science \& Policy 66:344-352. https://doi. org/10.1016/j.envsci.2016.05.006

Oberlack, C. 2017. Diagnosing institutional barriers and opportunities for adaptation to climate change. Mitigation and
Adaptation Strategies for Global Change 22:805-838. https://doi. org/10.1007/s11027-015-9699-z

Oberlack, C., and K. Eisenack. 2014. Alleviating barriers to urban climate change adaptation through international cooperation. Global Environmental Change 24:349-362. https://doi.org/10.1016/ j.gloenvcha.2013.08.016

Oberlack, C., and K. Eisenack. 2018. Archetypical barriers to adapting water governance in river basins to climate change. Journal of Institutional Economics 14:527-555. https://doi. org/10.1017/S1744137417000509

Oberlack, C., D. Sietz, E. Bürgi Bonanomi, A. De Bremond, J. Dell'Angelo, K. Eisenack, E. C. Ellis, G. Epstein, M. Giger, A. Heinimann, C. Kimmich, M. T. J. Kok, D. Manuel-Navarrete, P. Messerli, P. Meyfroidt, T. Václavík, and S. Villamayor-Tomas. 2019. Archetype analysis in sustainability research: meanings, motivations, and evidence-based policy making. Ecology and Society 24(2):26. https://doi.org/10.5751/ES-10747-240226

O'Brien, K. L., and H. C. Vogel, editors. 2003. Coping with climate variability: the use of seasonal climate forecasts in Southern Africa. Ashgate, Aldershot, UK.

O'Connor, R. E., B. Yarnal, R. Neff, R. Bord, N. Wiefek, C. Reenock, R. Shudak, C. L. Jocoy, P. Pascals, and C. G. Knight. 1999. Weather and climate extremes, climate change, and planning: views of community water system managers in Pennsylvania's Susquehanna River Basin. Journal of the American Water Resources Association 35:1411-1419. https://doi. org/10.1111/j.1752-1688.1999.tb04225.x

Okpara, U. T., L. C. Stringer, and A. J. Dougill. 2018. Integrating climate adaptation, water governance and conflict management policies in lake riparian zones: insights from African drylands. Environmental Science \& Policy 79:36-44. https://doi.org/10.1016/ j.envsci.2017.10.002

Ostrom, E. 2009. A general framework for analyzing sustainability of social-ecological systems. Science 325:419-422. https://doi.org/10.1126/science.1172133

Paavola, J., and W. N. Adger. 2006. Fair adaptation to climate change. Ecological Economics 56:594-609. https://doi.org/10.1016/ j.ecolecon.2005.03.015

Pahl-Wostl, C. 2009. A conceptual framework for analysing adaptive capacity and multi-level learning processes in resource governance regimes. Global Environmental Change 19:354-365. https://doi.org/10.1016/j.gloenvcha.2009.06.001

Pahl-Wostl, C., and C. Knieper. 2014. The capacity of water governance to deal with the climate change adaptation challenge: using fuzzy set qualitative comparative analysis to distinguish between polycentric, fragmented and centralized regimes. Global Environmental Change 29:139-154. https://doi.org/10.1016/j. gloenvcha.2014.09.003

Patterson, J., K. Schulz, J. Vervoort, S. van der Hel, O. Widerberg, C. Adler, M. Hurlbert, K. Anderton, M. Sethi, and A. Barau. 2017. Exploring the governance and politics of transformations towards sustainability. Environmental Innovation and Societal Transitions 24:1-16. https://doi.org/10.1016/j.eist.2016.09.001 
Pelling, M., and D. Manuel-Navarrete. 2011. From resilience to transformation: the adaptive cycle in two Mexican urban centers. Ecology and Society 16(2):11. https://doi.org/10.5751/ES-04038-160211

Pelling, M., K. O'Brien, and D. Matyas. 2015. Adaptation and transformation. Climatic Change 133:113-127. https://doi. org/10.1007/s10584-014-1303-0

Pulwarty, R. S., and R. Maia. 2015. Adaptation challenges in complex rivers around the world: the Guadiana and the Colorado basins. Water Resource Management 29:273-293. https://doi. org/10.1007/s11269-014-0885-7

R Core Team. 2018. R: A language and environment for statistical computing. R Foundation for Statistical Computing, Vienna, Austria.

Roggero, M. 2015. Adapting institutions: exploring climate adaptation through institutional economics and set relations. Ecological Economics 118:114-122. https://doi.org/10.1016/j. ecolecon.2015.07.022

Rudel, T. K. 2008. Meta-analyses of case studies: a method for studying regional and global environmental change. Global Environmental Change 18(1):18-25. https://doi.org/10.1016/j. gloenvcha.2007.06.001

Shepherd, P., J. Tansey, and H. Dowlatabadi. 2006. Context matters: what shapes adaptation to water stress in the Okanagan? Climatic Change 78:31-62. https://doi.org/10.1007/s10584-006-9093-7

Shobe, W., and D. Burtraw. 2012. Rethinking environmental federalism in a warming world. Climate Change Economics 3 (4):1250018. https://doi.org/10.1142/S2010007812500182

Sietz, D., U. Frey, M. Roggero, Y. Gong, N. Magliocca, R. Tan, P. Janssen, and T. Václavík. 2019. Archetype analysis in sustainability research: methodological portfolio and analytical frontiers. Ecology and Society 24(3):34. https://doi.org/10.5751/ ES-11103-240334

Simpkins, G. 2017. Progress in climate modelling. Nature Climate Change 7:684-685. https://doi.org/10.1038/nclimate3398

Singh, C., D. Joseph, A. Bazaz, G. Ziervogel, D. Spear, J. Krishnaswamy, M. Zaroug, and E. Kituyi. 2018. The utility of weather and climate information for adaptation decision-making: current uses and future prospects in Africa and India. Climate and Development 10:389-405. https://doi.org/10.1080/17565529.$\underline{2017.1318744}$

Smit, B., and J. Wandel. 2006. Adaptation, adaptive capacity, and vulnerability. Global Environmental Change 16:282-292. https:// doi.org/10.1016/j.gloenvcha.2006.03.008

Soares, M. B., M. Alexander, and S. Dessai. 2018. Sectoral use of climate information in Europe: a synoptic overview. Climate Services 9:5-20. https://doi.org/10.1016/j.cliser.2017.06.001

Soma, K., B. H. MacDonald, C. J. A. M. Termeer, and P. Opdam. 2016. Introduction article: informational governance and environmental sustainability. Current Opinion in Environmental Sustainability 18:131-139. https://doi.org/10.1016/j.cosust.2015.09.005

Storbjörk, S. 2010. 'It takes more to get a ship to change course': barriers for organizational learning and local climate adaptation in Sweden. Journal of Environmental Policy \& Planning 12:235-254. https://doi.org/10.1080/1523908X.2010.505414
Street, R. B. 2016. Towards a leading role on climate services in Europe: a research and innovation roadmap. Climate Services 1:2-5. https://doi.org/10.1016/j.cliser.2015.12.001

Tabara, J. D., N. Frantzeskaki, K. Hölscher, S. Pedde, K. Kok, F. Lamperti, J. H. Christensen, J. Jäger, and P. Berry. 2018. Positive tipping points in a rapidly warming world. Current Opinion in Environmental Sustainability 31:120-129. https://doi.org/10.1016/ j.cosust.2018.01.012

Tilleard, S., and J. Ford. 2016. Adaptation readiness and adaptive capacity of transboundary river basins. Climatic Change 137:575-591. https://doi.org/10.1007/s10584-016-1699-9

Tompkins, E. L., W. N. Adger, E. Boyd, S. Nicholson-Cole, K. Weatherhead, and N. Arnell. 2010. Observed adaptation to climate change: UK evidence of transition to a well-adapting society. Global Environmental Change 20:627-635. https://doi. org/10.1016/j.gloenvcha.2010.05.001

Tschakert, P., and K. A. Dietrich. 2010. Anticipatory learning for climate change adaptation and resilience. Ecology and Society 15 (2):11. https://doi.org/10.5751/ES-03335-150211

Vine, M. 2018. Learning to feel at home in the Anthropocene: from state of emergency to everyday experiments in California's historic drought. American Ethnologist 45:405-416. https://doi. org/10.1111/amet.12674

Wamsler, C., E. Brink, and C. Rivera. 2013. Planning for climate change in urban areas: from theory to practice. Journal of Cleaner Production 50:68-81. https://doi.org/10.1016/j.jclepro.2012.12.008

Whitely Binder, L. C. 2006. Climate change and watershed planning in Washington State. Journal of the American Water Resources Association 42(4):915-926. https://doi.org/10.1111/ j.1752-1688.2006.tb04504.x

Wilder, M., C. A. Scott, N. P. Pablos, R. G. Varady, G. M. Garfin, and J. McEvoy. 2010. Adapting across boundaries: climate change, social learning, and resilience in the U.S.-Mexico border region. Annals of the Association of American Geographers 100:917-928. https://doi.org/10.1080/00045608.2010.500235

Wise, R. M., I. Fazey, M. Stafford Smith, S. E. Park, H. C. Eakin, E. R. M. Archer Van Garderen, and B. Campbell. 2014. Reconceptualising adaptation to climate change as part of pathways of change and response. Global Environmental Change 28:325-336. https://doi.org/10.1016/j.gloenvcha.2013.12.002

Young, O. R. 2002. The institutional dimensions of environmental change: fit, interplay, and scale. MIT Press, Cambridge, Massachusetts, USA. https://doi.org/10.7551/ mitpress/3807.001.0001

Young, O. R. 2010. Institutional dynamics: resilience, vulnerability and adaptation in environmental and resource regimes. Global Environmental Change 20(3):378-385. https://doi. org/10.1016/j.gloenvcha.2009.10.001

Ziervogel, G., P. Johnston, M. Matthew, and P. Mukheibir. 2010. Using climate information for supporting climate change adaptation in water resource management in South Africa. Climatic Change 103:537-554. https://doi.org/10.1007/s10584-009-9771-3 
Ziervogel, G., E. A. van Garderen, and P. Price. 2016. Strengthening the knowledge-policy interface through coproduction of a climate adaptation plan: leveraging opportunities in Bergrivier Municipality, South Africa. Environment and Urbanization 28(2):455-474. https://doi.org/10.1177/0956247816647340 


\section{Appendix 1}

\section{CASE SELECTION AND CODING}

To reveal specific conditions that explain the appearance of opportunities for achieving climate adaptation, we conduct an archetype analysis of 26 selected case studies on water governance adaptation in river basins worldwide. The selection of these primary cases is based on the study of Oberlack and Eisenack (2018), where barriers to adaptation are thoroughly explored. This allows for examination of factors that enable adaptation opportunities in the context of already identified adaptation barriers. The studies were retrieved from the databases of Web of Science and Scopus so that the research is based on primary data and the articles are peer-reviewed. The final sample included primary studies on water governance adaptation in river basins worldwide from 20 scientific journals for the period of 1990-2015 (Table A1.1).

\begin{tabular}{l}
\hline \hline River basin \\
\hline Watersheds in \\
Washington State (USA)
\end{tabular}

McKenzie River (USA)

Yahara River (USA)

Columbia River (USA)

Susquehanna River (USA)

Bear river basin (USA)

Jaguaribe-Banabuiu

Basin, Itajai Basin

(Brazil) and Watersheds

in Arizona and Georgia

(USA)

Colorado River (Mexico, USA)

\section{Reference}

Binder, L. C. W. 2006. Climate change and watershed planning in Washington state. Journal of the American Water Resources Association 42: 915-926

Farley, K.A., C. Tague, and G.E. Grant. 2011. Vulnerability of water supply from the Oregon Cascades to changing climate: Linking science to users and policy. Global Environmental Change 21: 110-122

Gillon, S., E.G. Booth, and A.R. Rissman. 2015. Shifting drivers and static baselines in environmental governance: Challenges for improving and proving water quality outcomes. Regional Environmental Change 16: 759-775

Hamlet, A.F. 2011. Assessing water resources adaptive capacity to climate change impacts in the Pacific Northwest Region of North America. Hydrology and Earth System Sciences 15: 1427-1443

O'Connor, R.E., B. Yarnal, R. Neff, R. Bord, N. Wiefek, C. Reenock, R. Shudak, C.L. Jocoy, P. Pascals, and C.G. Knight. 1999. Weather and climate extremes, climate change, and planning: Views of Community Water System Managers in Pennsylvania's Susquehanna River Basin. Journal of the American Water Resources Association 35: 1411-1419

Welsh, L.W., J. Endter-Wada, R. Downard, and K.M. Kettenring. 2013. Developing adaptive capacity to droughts: The rationality of locality. Ecology and Society 18: 7

Kirchhoff, C.J., M.C. Lemos, and N.L. Engle. 2013. What influences climate information use in water management? The role of boundary organizations and governance regimes in Brazil and the U.S. Environmental Science \& Policy 26: 6-18

Pulwarty, R.S., and T.S. Melis. 2001. Climate extremes and adaptive management on the Colorado River: Lessons from the 
Arizona-Sonora region (Mexico, USA)

Colorado River (Mexico, USA) and Guadiana River (Portugal, Spain)

Southern Saskatchewan (Canada)

Okanagan (Canada)

Columbia River (Canada, USA)

Southern Saskatchewan (Canada) and Elqui (Chile)

Mendoza (Argentina) and Oldman River (Canada)

18 river basins in Brazil

Aconcagua River (Chile)

Aconcagua (Chile) and Rhone $(\mathrm{CH})$

Guadiana River (Portugal, Spain)

Multiple rivers in Denmark
1997-1998 ENSO event. Journal of Environmental Management 63: 307-324

Wilder, M., C.A. Scott, N.P. Pablos, R.G. Varady, G.M. Garfin, and J. McEvoy. 2010. Adapting across boundaries: climate change, social learning, and resilience in the U.S.-Mexico border region. Annals of the Association of American Geographers 100: 917-928

Pulwarty, R.S., and R. Maia. 2015. Adaptation Challenges in Complex Rivers Around the World: The Guadiana and the Colorado Basins. Water Resources Management 29: 273-293.

Hurlbert, M., H. Diaz, D.R. Corkal, and J. Warren. 2009. Climate change and water governance in Saskatchewan, Canada. International Journal of Climate Change Strategies and Management 1: 118-132

Shepherd, P., J. Tansey, and H. Dowlatabadi. 2006. Context Matters: What Shapes Adaptation to Water Stress in the Okanagan? Climatic Change 78: 31-62

Cosens, B.A., and M.K. Williams. 2012. Resilience and Water Governance: Adaptive Governance in the Columbia River Basin. Ecology and Society 17: 3

Hurlbert, M.A., and H. Diaz. 2013. Water Governance in Chile and Canada: A Comparison of Adaptive Characteristics. Ecology and Society 18: 61-83

Hurlbert, M.A., and E. Montana. 2015. Dimensions of Adaptive Water Governance and Drought in Argentina and Canada. Journal of Sustainable Development 8: 120-137

Engle, N.L., and M.C. Lemos. 2010. Unpacking governance: Building adaptive capacity to climate change of river basins in Brazil. Global Environmental Change 20: 4-13

Hill-Clarvis; M. and Allan; A. (2014): Adaptive capacity in a Chilean context: A questionable model for Latin America. Environmental Science \& Policy, 43, 78-90.

Hill, M. 2013. Adaptive capacity of water governance: cases from the Alps and the Andes. Mountain Research and Development 33: 248-259

Cots, F., J.D. Tàbara, D. McEvoy, S. Werners, and E. Roca. 2009. Cross-Border Organisations as an Adaptive Water Management Response to Climate Change: The Case of the Guadiana River Basin. Environment and Planning C 27: 876893

Larsen, S.V. 2011. Risk as a challenge in practice: Investigating climate change in water management. Regional Environmental Change 11: 111-122 
Orange-Senqu River

(Botswana, Lesotho, Namibia, South Africa)

Catchments in northeast Queensland (Australia)

Murray-Darling Basin (Australia)

Murray-Darling Basin (Australia)

Tweed River (Australia)

Elbe, Guadiana, Rhine, Nile, Orange, Amudarya
Kistin, E.J., and P.J. Ashton. 2008. Adapting to Change in Transboundary Rivers: An Analysis of Treaty Flexibility on the Orange-Senqu River Basin. International Journal of Water Resources Development 24: 385-400

Boer, H. 2010. Policy options for, and constraints on, effective adaptation for rivers and wetlands in northeast Queensland. Australasian Journal of Environmental Management 17: 154164

Pittock, J., and C.M. Finlayson. 2013. Climate change adaptation in the Murray-Darling Basin: Reducing resilience of wetlands with engineering. Australian Journal of Water Resources 12: 161-169

Wei, Y., J. Langford, I.R. Willett, S. Barlow, and C. Lyle. 2011. Is irrigated agriculture in the Murray Darling Basin well prepared to deal with reductions in water availability? Global Environmental Change 21: 906-916

Singh-Peterson, L., S. Serrao-Neumann, F. Crick, and I. Sporne. 2013. Planning for climate change across borders: Insights from the Gold Coast (QLD) - Tweed (NSW) region. Australian Planner 50: 148-156

Krysanova, V., C. Dickens, J. Timmerman, C. Varela-Ortega, M. Schlüter, K. Roest, P. Huntjens, F. Jaspers, H. Buiteveld, E. Moreno, J. de Pedraza Carrera, R. Slámová, M. Martínková, L. Blanco, P. Esteve, K. Pringle, C. Pahl-Wostl, and P. Kabat. 2010. Cross-Comparison of Climate Change Adaptation Strategies Across Large River Basins in Europe, Africa and Asia. Water Resources Management 24: 4121-4160

\section{Table A1.1 Primary case studies and river basins}

Since selected case studies contain heterogenic data and contexts, we refer to archetype analysis. In such instance, this approach appears to be valuable in that it generates two extremes that one could run to by trying to identify some regularities: context-specificity and overgeneralization. Archetypes are representative patterns of human-environmental interactions that are recurrently observed (Eisenack et al. 2006).

To identify interactions between various elements in adaptation situations coding methodology was used. Coding is a practical tool that is widely used for a qualitative analysis as it helps to systematically organize textual data. We coded text segments in the selected publications that describe situations, under which opportunities for adaptation emerge.

Development of codes for the present study on adaptation opportunities was based on the Ostrom's (2009) Social-Ecological Systems (SES) framework and on its modification for the climate adaptation context by Oberlack and Eisenack (2018). In most general terms, the SES framework encompasses outcomes (IO) in action situations framed by the core elements of the SES: resource systems (RS), resource units (RU), actors (A) and governance systems (GS) (Ostrom 2009). These elements or subsystems function within broader social-politicaleconomic settings (S) and in the context of related ecological systems (ECO). The modification of the framework for the climate adaptation context involves the addition of the category 
"adaptation option" (AO) to characterize adaptation examined in a primary study. The elements introduced above represent first-tier categories in the SES framework. More detailed codes that include explanatory factors form second- and third-tier attributes of the adjusted SES framework (e.g. GS51 stakeholder participation, RS221 climate stimuli not (yet) experienced: flood).

Coding of the data from primary case studies was processed electronically with the use of the software MaxQDA. The segments of the case studies that proved to include explanatory factors form second- and third-tier attributes of the adjusted SES framework were systematically coded. This was done using at least one interaction attribute (IO) and at least another one from the remaining SES elements (RS, A, GS, S, or AO). Rationale for requiring at least one interaction attribute (IO) is that opportunities for adaptation were operationalized as an interaction attribute: whenever an interaction attribute is observed, an opportunity is observed as well. The interaction attribute represents thus the outcome set for the analysis of the data produced through the coding process.

If the interaction attribute represents the outcome set, the remaining attributes constitute the model inherent to each causal statement coded herewith. The model encapsulates the results of interactions documented in primary studies and is the unit of analysis. Therefore, similar to Oberlack (2017) and Oberlack and Eisenack (2018) our meta-analysis is "model-centered" (Rudel 2008). Rationale for focusing the analysis on models is the following: 1) models represent explicit statements, thus requiring less interpretation than the case as a whole; 2) although they represent a reduction of complexity, they were done by someone with case-level knowledge; and 3) they passed the peer-review process, which, with all its limitations, should guarantee a minimum degree of reliability.

The fact that our research aims at exploring opportunities for climate adaptation, which is yet an emerging concept and is less addressed in comparison to the concept of barriers to adaptation, requires a consideration of a wider unit of observation. This means that a pure causal statement where one factor or combination of factors lead to a particular outcome (see Oberlack 2017) does not allow to describe the whole situation, under which opportunities for achieving adaptation arise. This is why we discerningly deviate from the approach of pure „,causal statements" as in Oberlack (2017) and Oberlack and Eisenack (2018) and consider models as „narratives“ that describe how a particular enabling factor (e.g. provision of climate information) coupled with other factors (attributes from the SES framework) leads to adaptation to climate change. In this sense, models encapsulate the presence of adaptation due to provision of climate information (e.g. in contrast to adaptation due to institutional change) and other attributes that help to describe situations in which such adaptation emerge, which makes it possible to identify its nature (incremental vs transformational).

Some examples of how causal statements were identified and coded will help clarify how models came about. For a practical illustration we refer to the paper of Kirchhoff et al. (2013). The paper addresses the role of water governance regimes and boundary organizations in shaping climate information use. Kirchhoff et al. (2013) build their study on the analysis of data obtained from surveys of river basin councils' members and interviews with water and disaster managers in the United States and Brazil. In search of causal statements, we look for text segments in the paper that explicitly link the characteristics of a particular situation to specific opportunities for adaptation. By doing so, we pay a particular attention that such explanations are found in direct presentation of the results and do not refer to some theoretical observations 
of other authors mentioned in the paper, i.e. they are not part of the literature review. Once such causality was observed, it was coded upon the common vocabulary of attributes.

One of the models we found in the study of Kirchhoff et al. (2013) crystallized out of the following text passage: "In Arizona, interviews with water managers working with CLIMAS revealed they were sensitive to climatic conditions and to other issues that affect water availability. These managers recognized that climate variability, and to a lesser extent climate change, may put water resources at increased risk in the future, given population growth and competition for water resources. Their perception of the vulnerability of water resources to climatic risks coupled with their goal of providing reliable water supplies was an important motivator for sustaining interaction with CLIMAS to produce usable climate information." We interpreted and coded this passage as following:

- Actor characteristics (A): this text segment allows for coding several actors' characteristics, such as "awareness of climate impacts", "understanding climate stimulus", "quality commitment", "availability of and accessibility to climate information". We assign these codes according to the sense that water managers' awareness of climate impacts and the recognition of the resource vulnerability to such impacts combined with a willingness to provide a reliable water supply sensitized water managers to information-seeking behavior.

- Resource system characteristics (RS): from the text passage, it becomes clear that the resource system is affected by a concurrent stimulus, a stimulus that is not related to climate issues, such as population growth in this case, but can likewise cause or exacerbate a water stress problem. We code it as a "concurrent stimuli".

- Adaptation option (AO): in order to understand how climate change may affect the water supply reliability in the future, water managers were seeking for relevant information to inform decision-making. This behavior of actors resulted in collaboration with the boundary organization aiming to generate usable information and thus to integrate climate impacts into planning and management settings. This is why we coded this as "adaptation responses due to interaction with boundary organizations".

- Governance system characteristics (GS): Such collaboration on information production requires an efficient interaction between actors and scientists from the boundary organization in order to reconcile information supply with a concrete demand, which we code as "coordination of data and knowledge" and "science-management interface".

- Opportunity for climate adaptation (IO): in the selected text segment, we can observe how the constellation of various factors (based on the SES framework) enable climate adaptation through production and use of climate information in planning and decisionmaking. Therefore, we consider sustained interaction with boundary organization as an opportunity for climate adaptation as it results in integration of climate impacts into governance and management practices, thus addressing a common barrier of water managers' risk aversion or skepticism.

For another example of model's extraction we refer to the study of Wilder et al. (2010) on adaptation of water resources in the U.S.-Mexico border region. The paper argues for a transboundary approach to increase regional adaptive capacity across borders. The study thus considers several cases of innovation in the regional strategies that aim at reconciling transboundary divide (Wilder et al. 2010). One of such innovations is the creation of a

\footnotetext{
${ }^{1}$ The Climate Assessment for the Southwest, a boundary organization in Arizona.
} 
transboundary assessment program that specifically tends to fill the gap in the scientific knowledge on groundwater resources in the region, and as a result has a high potential for improvements in sharing of climate information and its better integration into planning and decision-making practices. The following text segment of the article was considered as a model: "An emerging initiative, the U.S.-Mexico Transboundary Aquifer Assessment Program (TAAP), seeks to overcome these institutional and water-resource challenges through binational collaboration. Authorized by U.S. federal law and funded by annual budget appropriations, TAAP is implemented by the U.S. Geological Survey and the state water resources research institutes of Arizona, New Mexico, and Texas, with collaboration from Mexican federal, state, and local counterparts as well as IBWC ${ }^{2}$ and CILA ${ }^{2}$. (...) Over TAAP's brief lifetime, mutually defined priorities for Arizona's and Sonora's common Santa Cruz and San Pedro aquifers have been identified as vehicles for water for growth, adaptation to climate change, local aquifer-recharge programs, and institutional assessment of groundwater management asymmetries.". We interpreted this model as following:

- Actor characteristics (A): we code the willingness of actors to collaborate on information sharing, thus improving information flow and building a shared vision in the region, as "homogeneous interests". We also interpret such initiative as a way towards "understanding of interdependencies" in the social-ecological system of concern. The exchange and use of information to address inter alia climate change translated into the code of "availability and accessibility of climate information".

- Governance system characteristics (GS): from the governance perspective, such collaboration explicitly results into effective coordination between the two parties; this is why we correspondingly code it as "horizontal coordination".

- Adaptation option (AO): adaptation responses in this case are due to "creation of joint initiatives" in order to address climatic pressures.

- Opportunity for climate adaptation (IO): the creation of the information-sharing program represents an opportunity for achieving adaptation since it prompts collaboration among actors that leads to improving information flows. As a result, it has potential to develop a more systematic integration of new, relevant information into planning and management practices.

The coding procedure was repeated twice. If the codes were changed while coding a new study, the already coded studies were re-examined, and if necessary were subjected to the coding procedure a third time. In this way, through a stepwise coding, a detailed codebook was inductively developed and refined. In the final round, all models were checked for the congruence with the final codebook. This translated to a data set of 83 models, 110 attributes that hold for them, spanning across five different SES elements, and 6 different outcomes. The corresponding codebook is reported below (Table A1.2).

\begin{tabular}{lll}
\hline \hline Code & Interpretation \\
\hline $\mathrm{O}$ & Outcome & \\
$\mathrm{O} 1$ & $\begin{array}{l}\text { Opportunity to } \\
\text { adaptation is reported }\end{array}$ & $\begin{array}{l}\text { A case study reports and explains an opportunity } \\
\text { to climate change adaptation. }\end{array}$
\end{tabular}

$\mathrm{IO}$

Interaction outcome

\footnotetext{
${ }^{2}$ International Boundary and Water Commissions in the US and Mexico
} 
IO1 Enhancing climate information use

IO2 Adjusting government regulations

IO3 Integration

IO4 Learning

IO5 Collaboration and coordination

IO6

Capacity building

A

A1

A11

A12

A13

A14

A2

A21

A22

A23

A24

A25

A26
Actors

Individual knowledge

Understanding climate stimulus

Understanding SES

Understanding

interdependencies in a SES

Awareness of climate change impacts

Homogenous beliefs, interests and priorities Homogeneous beliefs

Interest in climate change

Trust building among actors

Political (public) acceptability

Quality commitment

Homogeneous interests

Access to material resources
Enhancing the usability of relevant information in planning and management practices, necessary for responding to longer-term changes (intra-annual variability, evaluation of data on extremes and mean values, climate projections).

Changes in government regulations or institutional design.

Integrating various aspects (social, economic, climate, political, etc.) as well as all actors involved at different levels to prepare responsive actions to climate change adaptation.

Various social learning processes that help to address climate adaptation needs.

Involvement of the interested and affected stakeholders and/or agencies (building networks or coalitions) for the joint cooperation (information, knowledge and resources) to increase adaptive capacity.

Provision of information, water accounting and necessary resources either from government or from other institutions in order to favor adaptation.

Actors understand how climate change may affect the resource system.

Actors have a good understanding of the system they operate in.

Actors have a good understanding of interdependent elements of the system they operate in.

Actors are aware about climate impacts or they have a perception to be exposed to climate them.

Actors have homogeneous beliefs about climate change and its impacts.

Interest in climate change of individual actors who perceive the vulnerability of the resource system towards climate impacts.

All actors are pursuing cooperative strategies and common interests.

Adaptation related actions do not conflict with political values.

A goal to provide a reliable water supply.

Development of homogeneous beliefs among actors as well as building a common vision.

Actors possess resources necessary for the adaptation process. 
A31

A32

A4

A41

A42

A43

A44

A45

A46

A5

A51

RS

RS1

RS11

RS12

RS2

RS21

RS211

RS212

RS213

RS214

RS215

RS22

RS221

RS222

RS223
Available financing

Increasing technical

capacity

Access to information resources

Use of modelling tools

Available data on

climate change

projections at the local

scale

Information on the

system and on climate

events

Provision and use of

new/additional

information

Use of information on

past events

Communication of

information

Staff resources

High professional staff

Resource system

Size and scale of a

resource system

A resource system is embedded in a larger water system

Upstream-downstream effects

Stimuli and exposure

Current climate stimuli

Drought

Flood

High variability

Low variability

Other

Climate stimuli not (yet) experienced

Flood

Drought

Other
Actors have access to funding means.

Actors are able to increase technical capacity to prepare adaptive responses to climate impacts.

The use of modelling tools for predictions and analysis of climate impacts.

There is available data on climate change projections at the local scale.

The use of information on the system actors are operating in and on local climate events in decision-making.

The use of new, updated/additional information on climate and/or climate impacts in decisionmaking.

The use of information on past climate extreme events.

Dissemination of relevant climate information and demonstration of climate impacts to managers in order to increase awareness about climate change.

Professional managers show familiarity with climate variability and change, helping to bring climate impacts into decision-making process.

The examined resource system is a part of a larger system, which is relevant for analysis.

A particular positioning of actors of the resource system that has implications for decision-making.

Current climate stimuli that affect the resource system.

Expected climate stimuli in view of climate change. 


$\begin{array}{lll}\text { RS3 } & \begin{array}{l}\text { Current state of a } \\ \text { resource system } \\ \text { Degradation of a system }\end{array} & \begin{array}{l}\text { The examined resource system is in a degraded } \\ \text { condition. }\end{array} \\ \text { RS31 } & \text { Water pollution } & \begin{array}{l}\text { Pollution of water resources is a critical issue and } \\ \text { has impact on its quality. }\end{array}\end{array}$

RS4 Concurrent stimuli

\begin{tabular}{|c|c|}
\hline GS & Governance system \\
\hline GS1 & Scale of institutions \\
\hline GS11 & $\begin{array}{l}\text { Continuity in formal } \\
\text { capacity }\end{array}$ \\
\hline GS12 & $\begin{array}{l}\text { Change in } \\
\text { administration }\end{array}$ \\
\hline GS2 & $\begin{array}{l}\text { Adaptiveness of } \\
\text { institutions }\end{array}$ \\
\hline GS21 & Flexibility of institutions \\
\hline GS22 & $\begin{array}{l}\text { Complex management } \\
\text { system }\end{array}$ \\
\hline
\end{tabular}

GS23 Institutional learning

GS3 Social connectivity

GS31 Vertical coordination

GS32 Horizontal coordination

GS321 Coordination of data and knowledge

GS322 Common efforts and resources

$\begin{array}{ll}\text { GS33 } & \begin{array}{l}\text { Top-down decision- } \\ \text { making }\end{array} \\ \text { GS34 } & \begin{array}{l}\text { Decentralized } \\ \text { governance system }\end{array}\end{array}$

The resource system is affected by a concurrent stimulus, e.g. development processes, population growth, etc.

Temporal boundaries of institutional operation.

Continuity in formal capacity after the planning process has been completed.

Changes in administration due to staff rotation (e.g. as a result of the elections).

The extent to which institutions are able to be changed.

Flexibility in procedures for institutional change.

Management or governance system is considered complex due to many actors involved in managing process.

Learning process as a result of information and knowledge flow across all levels of government.

Characteristics of institutionalised procedures (i.e. chains of actions, events and outcomes) and networks (i.e. connections between multiple positions and actors) that connect actors within and across tiers of social organisation.

Coordination between actors of the analysed resource system and other governance levels.

Coordination between different departments of the same-level public organizations.

Coordination between actors/ different departments of public organizations at the samelevel of decision-making for data and knowledge exchange.

Coordination between actors/ different departments of public organizations at the samelevel of decision-making for joint efforts and resources.

Decision-making process is based on a hierarchical, top-down manner.

The governance system is characterized as decentralized. 
GS41 Institutional incentives and priorities

GS411 Long-term focus

GS 412 Efficiency and conservation are included/prioritized

GS413 Rules based on

GS414 Updates historical hydrology

GS42 Responsibilities

GS421 Clear not-fragmented responsibilities/decisionmaking

GS422 Fragmented responsibilities

GS43 Property rights

GS431 Secure property rights

GS431a Secure property rights with fixed allocations

Operational rules prompt long-term planning.

Adaptive needs of ecosystems are prioritised.

Operational rules are based on historic hydrologic conditions.

Regular updates of planning documentation.

Attributes of position and choice rules that regulate the positions of participants and their actions associated to these positions.

Responsibilities are clear.

There are multiple independent actors of decisionmaking that are not coordinated.

Security of property rights is high.

Security of property rights is high and they provide their holders with the right to a fixed amount of a resource (e.g. prior appropriation rule).

GS5

Actors

GS51 Stakeholder

participation

GS52 Leadership

GS6 Social learning

GS61 Effective science-

policy/science-

management interface

GS62 Institutional learning

GS63 Learning from other examples

GS64 Context specific

GS65 Learning is based on past experiences

GS66 Education of stakeholders

Eligibility of stakeholders to participate in decision-making.

There is a strong leader in a stakeholder group that can influence decision-making process.

Institutional attributes that shape how information, knowledge, values and preferences are constructed, communicated and accepted among participants.

The science-policy/science-management interface is effective in terms of social learning.

Effective institutional learning, incl. learning process as a result of information and knowledge flow across all levels of government.

Learning from other examples or areas takes place.

Social learning is based on the understanding of interdependencies of actors in SES.

Learning is based on past experiences with climate variability.

Communication with and education of stakeholders (and public). 
GS7

Control

GS71 Centralized coordinated

GS72 Polycentric

$\begin{array}{ll}\text { AO } & \text { Adaptation Option } \\ \text { AO1 } & \text { Reactive adaptation }\end{array}$

$\mathrm{AO} 2$

Adaptation responses complementary with

AO21 Nature conservation and management acts

AO22 State planning/management acts

$\mathrm{AO} 23$

Water allocation management

AO24 Water conservation program

AO25 Water agreements

AO26 Adaptive management program

AO3 Formation of institutional bodies

AO31 Local watershed units

AO32 Joint institutional arrangements

AO33 Basin-based councils AO34 Interface organisations
Type of control over the system's management and over the aggregate outcomes of an adaptation situation.

Distribution of power and authority is wellcoordinated under a hierarchical governance mode.

Distribution of power and authority among various well-coordinated centres.

Fast responses that include prompt decisions in order to reduce the damage caused by climate extremes.

Adaptation responses are complementary with various management and planning acts/programs.
Adaptation requires formation of various types of institutional bodies for its planning and implementation.

Table A1.2 Codebook

\section{DATA PROCESSING: ARCHETYPE ANALYSIS USING R}

\section{Step 1: Definition of the outcome set}

Each model extracted from the literature through the coding process described so far is linked to an outcome. Similarly, to all other SES elements above, interactions/opportunities (IO) are coded in a nested form. As a result, outcomes vary both in qualitative terms (IO1 vs. IO2 vs. IO3) and in terms of specificity (IO1 vs. IO11 vs. IO111). Furthermore, models vary in terms of how often they are observed, implying that some opportunities appear in a large number of models, whereas other ones appear more seldom. Finally, the nested nature of the SES framework implies that instances of e.g. IO111 are a subset of the instances of IO11, which in turn are a subset of $\mathrm{IO} 1$ - as for all remaining entries in the codebook. 
Because of the qualitative difference between the various outcomes, each individual instance (IO1, IO12, etc.) is worth an analysis on its own account. This corresponds to running the algorithm described herewith with a different outcome set. Space and the specificity of the research focus of the paper do not allow for an analysis of all instances of opportunities observed. Since the concept of archetype implies reappearing phenomena, suitable outcomes are those that are frequently observed. Figure A1.1 below shows how frequently each instance of opportunity/driver is observed.

Given the distribution shown in Figure A1.1, IO1 ("the provision of climate information") seems the most feasible option: being observed in almost every other model (38 out of 83), it is specific enough to be qualitatively meaningful, yet it is generic enough to be observed in a large pool of models.

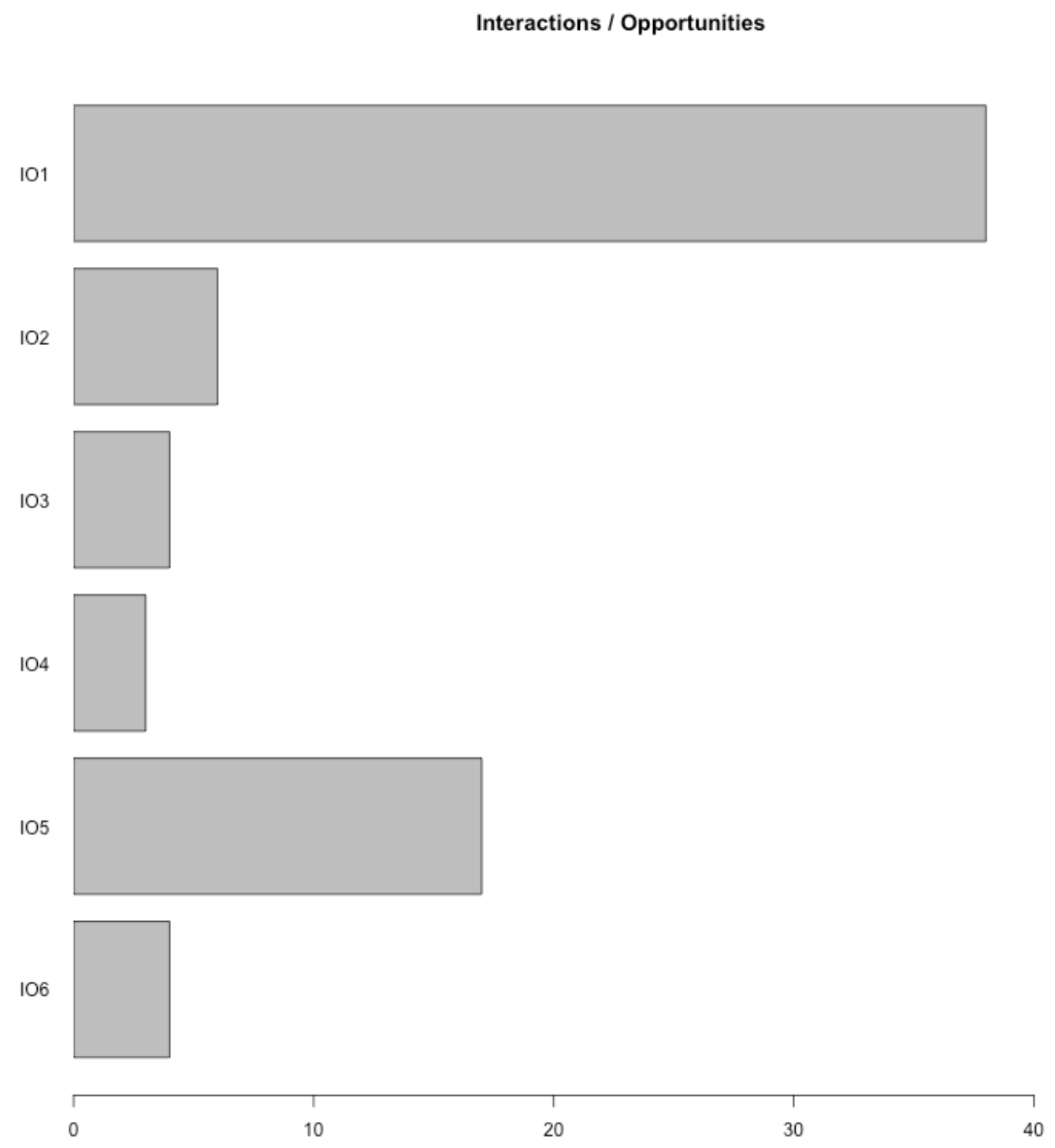

Figure A1.1: Number of models for each type of opportunity.

\section{Step 2: identification of archetypes}

To identify archetypical situations under which opportunities to adapt emerge, we processed the data on the models' attributes using R. We specifically wrote an algorithm that (ideally) 
computes all possible archetypes obtainable from the above mentioned 110 attributes, populates them with the available data, and tests whether the specific models identified by each archetype are consistently linked to the outcome set: IO1 or "enhancing the provision of climate information", the type of opportunity identified above.

Doing the above raises a few challenges. A key challenge is linked to computing all possible archetypes. The number of all possible combinations of 110 elements is the factorial of 110 , which is in excess of $10^{178}$. To express all theoretically possible archetypes alone is thus a computationally very intensive task - the more so if one also wants to verify which of the observed models is contained in each of them and link them to the outcome set. A more manageable task is instead to compute all possible archetypes that involve one (or no) attribute for each of those SES elements relevant for this study (RS, A, GS, S, and AO). Furthermore, attributes can be omitted if they are observed too seldom to appear in an archetype ${ }^{3}$, or whether they are too general to be of interest. Eliminating such attributes further reduces the combinatorial space in which archetypes may potentially come about.

The above shortcuts produce a grand total of 53.312 computationally possible configurations of attributes. To obtain the corresponding models and test for the presence of IO1 programmatically is a feasible and rather straightforward task. That is however not a guarantee that the amount of relevant archetypes (those leading to IO1), will be in any way manageable. In order to achieve that, additional criteria are necessary. We have used a total of four, as detailed out below.

- The first of the four criteria corresponds to selecting those archetypes where IO1 is indeed consistently observed. Any given combination of SES elements (say: $\mathrm{A} 131 * \mathrm{GS} 21 * \mathrm{AO} 3$ ) yields a number of models which may or may not feature IO1 - for instance, some may feature IO2. In this first step, archetypes are retained if the models they yield only feature IO1. Please note that, while models featuring e.g. IO2 will lead the corresponding archetype to be discarded, models featuring more specific opportunities than IO1 (e.g. IO11 or IO123) will be retained. From an operational point of view, for each set of models identified by a particular archetype set-theoretic consistency as a sufficient condition for IO1 is calculated. Archetypes are retained if that consistency is 1.0 , implying full consistency.

- Second and third, archetypes are required to feature in at least two models across at least two different papers. This two-fold requirement operationalizes the concept of archetypes as recurring patterns, taking into account that multiple models within the same archetypes may all come from the same publication and are thus only questionably "recurring". It is consistent with Oberlack and Eisenack (2018).

- Fourth, archetypes are selected based on their complexity, understood as the number of SES elements featuring therein. Specifically, archetypes are retained if they feature at least two different elements. We thus restrict the analysis to archetypes expressing the combination of different SES elements. Please note that this restriction has two

\footnotetext{
${ }^{3}$ By definition, an attribute observed only once cannot be observed in at least two models or papers. It thus cannot characterize an archetype, since archetypes need to be observed in at least two models from two different papers. More generally, the more seldom an attribute, the more unlikely it can appear in conjunction with other attributes. For the present analysis, the threshold has been set at three: attributes observed less than that were excluded from the analysis.
} 
components: 1) that the attributes characterizing the archetypes must be more than one; and 2) that they must belong to different elements. As a result, archetypes made up of individual attributes are eliminated. Recall that archetypes are generated by computing all possible archetypes that involve one (or no) attribute for each SES element (RS, A, GS, S, or AO), which does not exclude archetypes encompassing a single attribute. Single-attribute archetypes, however, hardly fit the nature of archetypes as patterns. Leaving them out of the analysis is thus in order. Furthermore, archetypes encompassing more attributes from the same elements (e.g. GS12*GS15) would be eliminated as well. Such archetypes were not generated in the first place, though, as doing so would cause the number of potential archetypes to skyrocket. A mathematical proof is available here $^{4}$, but the reader can simply grasp this by comparing the amount of theoretically possible combinations of attributes $\left(10^{178}\right)$ with the amount of archetypes obtained by combining one (or no) attribute for each individual SES element (53.312).

A first selection is then performed based on the four abovementioned criteria, leading to 15 relevant combinations of attributes. Although much more manageable, a similar selection of archetypes cannot ensure a meaningful diversity. The reader can easily grasp the issue by comparing a combination of attributes such as e.g. A13*GS21*AO31 with another one such as A131*GS21*AO3: both have the same degree of complexity, as they both involve three different SES elements; however, the former is more specific concerning adaptation outcomes (AO31 vs. AO3), whereas the latter is more specific concerning actor characteristics (A131 vs. A13).

What happens here is that any two combinations of attributes can be fundamentally similar, and increasing specificity on one hand can be off-set by decreasing specificity on another aspect of the archetype. These raises the question whether all archetypes characterized by a given selection of SES elements represent individually relevant archetypes, or whether they are better considered as variants of the same archetype, thus requiring further selection. The latter approach seems more meaningful in analytical terms, as it would ideally lead to results which are more parsimonious, and thus more amenable to theoretical interpretation.

In order ensure a degree of distinction between archetypes, these are first sorted lexicographically, based on complexity and, by equal complexity, by number of models. Based on that ranking, a last selection is performed, aiming at archetypes that, although different in terms of the attributes characterizing them, end up identifying the same set of models. Specifically, the selection process involves a pairwise comparison of archetypes, starting from the top ones and moving down the ranking. In each comparison, archetypes are eliminated if the models they encompass overlap beyond a certain threshold (50\%). This means: if two archetypes overlap for more than 50 percent in terms of the models they identify, they are considered variants of the same archetype. In that case, the lower one in the ranking is eliminated. Note that, by proceeding in this way, individual models can be captured by different

\footnotetext{
${ }^{4}$ Assume $y=a+b$, where $a>1$ and $b>1$. It follows that $! y=(a+b) *(a+b-1) *(\ldots)$, so that $! y>$ $(a+b) *(a+b-1)$, meaning $! y>a^{2}+b^{2}+2 a b-a-b$. That can be expressed as $! y>a b+k$, where $k=a^{2}+b^{2}+a b-a-b$. It follows that $k>0$ because $a^{2}+b^{2}+a b>a+b$. Hence, $! y>a b+k$, hence ! $y>a b$, q.e.d.

Note that cases where either $a$ or $b$ are either nil or simply smaller than one are out of scope here, as they would respectively represent an entirely empty set $(a=b=0)$, a single-attribute archetype $(a=0$ or $b=0)$ non-integer or even negative amounts $(a<1$ or $b<1$ ).
} 
archetypes. What the procedure does not allow is that archetypes identify sets of models that overlap beyond a certain threshold.

When the comparisons are completed, the archetypes left in the ranking meet all the conditions needed in order to qualify as archetypes: they are linked to a certain "outcome" (IO1); they represent sets of attributes; they are observed in multiple cases (here: models from different articles); multiple archetypes can be observed in individual cases, yet different archetypes encompass sets of cases that differ from one another. Additionally, their complexity (how many attributes) is chosen systematically, as a result of the process described above.

Based on the dataset at stake, the number of archetypes identified with the procedure described so far amounts to the following 6 :

\begin{tabular}{|c|c|c|c|c|}
\hline Archetype & ATs & $\begin{array}{l}\text { Number of } \\
\text { models }\end{array}$ & Papers & Models \\
\hline $\begin{array}{l}\text { Adaptation as } \\
\text { collective action }\end{array}$ & $\mathrm{AO} 32, \mathrm{~A} 23, \mathrm{GS} 32$ & 2 & 2 & $\begin{array}{l}\text { Kistin and Ashton } 2008 \\
(02), \text { Wilder et al. } 2010 \\
(01)\end{array}$ \\
\hline $\begin{array}{l}\text { Adaptation through } \\
\text { local knowledge }\end{array}$ & AO31, A14 & 3 & 3 & $\begin{array}{l}\text { Binder } 2006(09), \\
\text { Hurlbert and Diaz } 2013 \\
(04), O^{\prime} \text { Connor et al. } \\
1999(02)\end{array}$ \\
\hline Adaptation "fit" & AO31, GS41 & 3 & 2 & $\begin{array}{l}\text { Binder } 2006(07) \text {, } \\
\text { Binder } 2006(08), \\
\text { Hamlet } 2011(03)\end{array}$ \\
\hline $\begin{array}{l}\text { Knowledge in } \\
\text { context }\end{array}$ & $\mathrm{AO} 31, \mathrm{~A} 42$ & 2 & 2 & 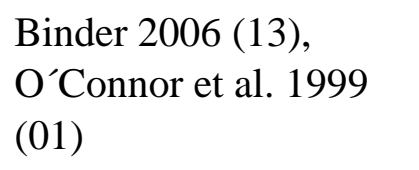 \\
\hline System evolution & RS21, GS411 & 2 & 2 & $\begin{array}{l}\text { Kirchhoff et al. } 2013 \\
(03), \text { Pulwarty and Maia } \\
2015 \text { (03) }\end{array}$ \\
\hline Learning & AC14, GS41 & 2 & 2 & $\begin{array}{l}\text { Boer } 2010(03) \text {, Farley } \\
\text { et al. } 2011(05)\end{array}$ \\
\hline
\end{tabular}

Table A1.3 Archetypes of opportunities for enhancing climate information use.

The attributes encompassed thereby are the following:

\begin{tabular}{lll}
\hline \hline ID & Code & Label \\
\hline 18 & AO31 & local watershed units \\
19 & AO32 & joint institutional arrangements \\
38 & RS21 & current climate stimuli \\
74 & A14 & awareness of climate impacts
\end{tabular}


78 A23 trust building among actors

88 A42 available data on climate projections at the local scale

105 GS32 horizontal coordination

112 GS41 institutional incentives and priorities

113 GS411 long-term focus

Table A1.4 Attributes of archetypes. 